Article

\title{
A Study on China's Urban Electricity Productivity Convergence with Spatial Smooth Transition Effect
}

\author{
Ming Luo, Ruguo Fan * and Yingqing Zhang \\ Economics and Management School, Wuhan University, No. 299 Bayi Road, Wuhan 430072, China; \\ luoming831@163.com (M.L.); yqzhang422@163.com (Y.Z.) \\ * Correspondence: rgfan@whu.edu.cn; Tel.: +86-189-71-647-078
}

Received: 19 June 2017; Accepted: 28 July 2017; Published: 2 August 2017

\begin{abstract}
This paper analyzes the absolute convergence of urban electricity productivity in China during 1990-2011, applying Spatial Error Smooth Transition Auto-regression Model, and examines the spatial effect in convergence process. Then it analyzes the stage characteristics of electricity productivity convergence during the process of electricity market reformation and the conditional convergence which is affected by the urban economy. According to the results of our research, there exists significant absolute convergence of urban electricity productivity in China, and the spatial effect, especially spatial smooth transition effect, significantly enhance the convergence of urban electricity productivity. Since the electricity market reformation in 2002, significant stage characteristics exist in convergence of urban electricity productivity. The convergence rate of electricity productivity before 2002 is obviously lower than the one during the whole sample period, also the one after 2002 and the spatial nonlinear effect strengthens during the later period with marketization in electricity market and stricter regulation on energy conservation. The urban economy also affects the convergence of urban electricity productivity, while it does not promote the convergence rate because the high proportion of electricity-intensive industry in cities of western and northeastern region. At the conclusion of our paper, we put forward policy suggestions with the objective of narrowing the gap of urban electricity productivity and realizing sustainable urban development.
\end{abstract}

Keywords: electricity productivity; convergence; spatial effect; spatial error smooth transition Auto-Regression Model

\section{Introduction}

Currently, electricity plays an increasingly significant role in urban economic development in China. Growing electricity demand becomes a serious problem for urban sustainable development. In recent decades, China has achieved a big breakthrough in urban energy saving and carbon emission reduction, while the regional unbalance is also a growing threat to urban sustainable development. To cope with it, it is important to not only improve electricity utilization efficiency, but also realize regional coordinating development in electricity utilization. Electricity productivity is defined as the ratio of economic output and electricity consumption [1], and it is an important index for measuring electricity utilization efficiency. Since narrowing regional gap of electricity productivity is considered as one of the most crucial approaches to balance economic development, a growing number of studies start to focus on the performance of regional coordinating development of electricity productivity, namely the convergence of electricity productivity.

The concept of productivity convergence has its roots in the traditional Solow-Swan neoclassical growth model with its central notion of a transitional growth path toward a steady state [2,3]. Then a growth model that takes energy factor into consideration was constructed by Moon and Sonn, and the exploration of the existence of energy utilization convergence began [4]. Based on Moon-Sonn Model, 
Mielnikand Goldemberg make an empirical analysis on convergence of energy efficiency among the representative developed countries and developing countries [5]. Recently, a number of papers have explored convergence issues in energy intensity or productivity [6-10].

Overall, the methods widely used to analyze productivity convergence are $\beta$ convergence model and $\sigma$ convergence model. However, it is hard to obtain stable results through $\sigma$ convergence model to some extent [11]. Therefore, the productivity convergence issue is more commonly studied by $\beta$ convergence model [12] and the analyzing framework is improved continuously [13-18]. The convergence of regional energy productivity or efficiency in China attracts many scholars to devote substantial attention. Qi et al. examine that there exists $\beta$ convergence of energy intensity in China and it is affected by regional economic development [19]. Some scholars make research on energy productivity convergence based on Spatial Econometrics Model, concluding that spatial correlation effect is also a significant factor to influence convergence of energy productivity $[20,21]$ and it shows stage characteristics during the sample period [22].

Although many studies focus on energy productivity convergence, scholars seldom pay attention to electricity productivity convergence. Maza and Villaverde indicate that electricity efficiency shows a weak convergence on the basis of data of 98 countries selected [23]. Liddlealso states that there exists convergence of electricity efficiency in IEA (International Energy Agency) countries while its convergence rate is lower than the total energy efficiency [24]. Herrerias and Liu explore the convergence of provincial electricity intensity in China in view of Economics Geography and it indicates that there exists threshold effect in the process of convergence [25].

The references above indicate that the existing literature on convergence of electricity productivity suffers from two limitations. Firstly, the literature only considers the convergence of electricity productivity in temporal dimension. However, similar to general energy issues [26], the convergence of electricity productivity can be affected by spatial effect, because that technological development has rendered communication among regions more convenient, resulting in technology spillovers and diffusion effects among regions $[20,21]$. Although some scholars study the spatial effect in convergence of energy productivity, they only focus on spatial correlation effect while spatial nonlinear effect, namely spatial regime switching, is ignored. A reason to explain why spatial regime switching appears is that competitions among cities exist in the implementation of energy saving policy, which indicates that city government will make energy-saving target and policy implementing intensity based on comparison between its own electricity productivity and the one of its surrounding cities. As previous studies neglect spatial nonlinear effects, they are unlikely to precisely identify the formation mechanism of convergence of electricity productivity. Secondly, existing studies analyzing convergence in electricity productivity in China has yet to account for policy influence. However, given China's Electricity Market Reformation that occurred in 2002, in which the electricity price system is improved to facilitate reasonable allocation of electricity resource and the electricity technology level is also promoted, this policy implementation is bound to affect China's electricity productivity, resulting in stage characteristics in convergence of electricity productivity.

Different from previous studies, this paper will focus on the issues mentioned above, namely spatial nonlinear effect and policy influence in urban electricity productivity convergence. To begin with, we will apply Spatial Error STAR (Smooth Transition Auto-regression) Model, depicting spatial nonlinear effect by smooth transition method, to estimate the absolute convergence model of urban electricity productivity, comprehensively considering the spatial correlation effect and spatial smooth transition effect and comparing the calculation with the results of other three methods. Then, we divide the sample period into two stages with 2002 as the dividing line, analyzing the stage characteristics in convergence of urban electricity productivity with Electricity Market Reformation processing. Then, we use Spatial Error STAR Model to estimate the conditional convergence model and explore the influence of urban economy on convergence of electricity productivity. It is significant to contribute to design appropriate energy policies and provide a basis for decisions regarding the urban electricity productivity convergence. 
The rest of the paper is structured as follows. The method of the Spatial Error STAR Model and data used in this paper are briefly introduced in Section 2. The estimations of urban electricity productivity convergence model by Spatial Error STAR Model during the period from 1990 to 2011 are discussed in Section 3. The final section presents the conclusions and some policy implications.

\section{Method and Data}

\subsection{Method}

\subsubsection{Convergence Model of Urban Electricity Productivity}

Existing literatures shows that the convergence of energy productivity can be analyzed by $\beta$ Convergence Model and it is also an effective method for electricity productivity, denoting that cities with lower initial electricity productivity will increase with a higher level. In general, $\beta$ Convergence in economics model can be classified into $\beta$ absolute convergence and $\beta$ conditional convergence. For electricity productivity (EP), $\beta$ absolute convergence model can be constructed as follow:

$$
\ln \left(\frac{E P_{i, t+T}}{E P_{i, t}}\right)=\beta_{0}+\beta_{1} \ln E P_{i, t}+\mu_{i, t}
$$

If the value of $\beta_{1}$ is negative, it is indicated that, under the homogeneous condition, the change of urban electricity productivity negatively correlated with initial urban electricity productivity, namely there exists $\beta$ absolute convergence.

The convergence of urban electricity productivity is inevitably affected by variation of urban economy, which leads to the $\beta$ conditional convergence. To study the effect from variation of urban economy, $\beta$ conditional convergence model is constructed considering economic development:

$$
\ln \left(\frac{E P_{i, t+T}}{E P_{i, t}}\right)=\beta_{0}+\beta_{1} \ln E P_{i, t}+\theta Z_{i, t}+\mu_{i, t}
$$

Similarly, if the value of $\beta_{1}$ is negative, it is indicated that under heterogeneous urban economy, there exists $\beta$ conditional convergence.

\subsubsection{Convergence Model of Urban Electricity Productivity with Spatial Effect}

The convergence of urban electricity productivity derives from the interaction among regions. Therefore, the spatial effect plays an important role in converging process of urban electricity productivity. Some scholars use traditional spatial econometrics model to analyze the convergence of electricity productivity with spatial correlation effect. While some researchers have proved that there exists nonlinear characteristics in the evolution of electricity productivity [25]. Traditional spatial econometrics models, Spatial Lag Model and Spatial Error Model, are not able to characterize the nonlinearity. Geographically Weighted Regression (GWR) model is an effective way to deal with the spatial heterogeneity and it can depict the nonlinearity to some extent, while it has some shortcomings: (1) it is difficult to examine the spatial nonlinearity by parametric test; (2) GWR model is estimated by Locally Weighted Regression Method, which is realized by distance decay-based function, leading to a high information loss of data; and (3) it is easily affected by co-linearity and outliers.

Spatial Smooth Transition Auto-regression Model (Spatial STAR Model) is also an effective method to deal with the continuous and smooth spatial nonlinear effect, and it will not be disturbed by the issues mentioned above in GWR model. Smooth Transition Effect is a common nonlinear phenomenon in economics, and Smooth Transition Auto Regression (STAR) Model is widely used to depict such phenomenon in econometrics analysis, especially in Time Series Analysis [27,28]. However, it is seldom used in Spatial Econometrics Analysis. Basile starts to use spatial econometrics to depict the spatial nonlinear characteristics by semi-parameter method [29], while it is hard to exhibit the spatial switching among different regimes and its transition effect is not smooth. Pede et al. deal with the 
spatial nonlinear effect by adding the spatial effect into smooth transition function and construct the Spatial STAR Model based on the traditional Spatial Econometrics Model [30]. Spatial Error STAR Model, which is a combination of Spatial STAR model and Spatial Error Model, not considers spatial correlation effect, but also deals with the spatial nonlinear effect and spatial smooth switching among different regimes.

According to Pede et al., Spatial Error STAR Model is an econometrics tool that introduces spatial smooth transition effect into spatial error model. Firstly, spatial error model can be constructed as:

$$
y=X \alpha+\mu, \mu=\rho W \mu+e
$$

where the parameter $\alpha$ is only a constant.

Then the smooth transition effect can be considered if the regime is added into the model. The model can be constructed as follow.

$$
\begin{aligned}
& y=X \alpha_{1} \circ[1-G(s ; \gamma, c)]+X \alpha_{2} \circ G(s ; \gamma, c)+\mu \\
& \mu=\rho W \mu+e
\end{aligned}
$$

where $G(s ; \gamma, c)$ is the smooth transition function and $\circ$ is the Hadamard product (element-by-element multiplication). Formula (4) manifests that Spatial Error STAR Model can not only analyze the spatial correlation effect, but also depict the regime switching by smooth transition function $G(s ; \gamma, c)$ whose value ranges from 0 to 1 . Commonly, $G(x)$ performs logistic function or exponential function. Take logistics mooth transition function as an example:

$$
G\left(s_{i} ; \gamma, c\right)=\frac{1}{1+\exp \left[-\gamma\left(s_{i}-c\right) / \sigma_{s}\right]}
$$

where $s$ is smooth transition variable. Similar to Time Series Analysis, spatial lag term $W X$ can be used as smooth transition variable in Spatial Error STAR Model, which reveals that the regime switches in spatial dimension. $\gamma$ is slope of smooth transition function and $\mathrm{c}$ and $\sigma_{s}$ are respectively threshold value and standard deviation of smooth transition variable.

After appropriate smooth transition function and variable have been selected, the Spatial Error STAR Model can be established as follow.

$$
\begin{aligned}
& y=X \beta+X \delta \circ G(W X ; \gamma, c)+\mu \\
& \mu=\rho W \mu+e
\end{aligned}
$$

where, $\beta=\alpha_{1}, \delta=\alpha_{2}-\alpha_{1}$. If $\delta=0$, the model becomes spatial error model; if $\rho=0$, the model becomes spatial STAR model; and if $\delta=0$ and $\rho=0$, the model becomes traditional OLS model.

According to model above-mentioned, evolution of urban electricity productivity is not only affected by spatial correlation effect but also spatial regime switching. Suppose its regimes switching is a smooth transition process, we can establish the $\beta$ absolute convergence model of urban electricity productivity based on Spatial Error STAR Model as follow.

$$
\begin{aligned}
& \ln \left(\frac{E P_{i, t+T}}{E P_{i, t}}\right)=\beta_{0}+\beta_{1} \ln E P_{i, t}+\left(\delta_{0}+\delta_{1} \ln E P_{i, t}\right) G\left(W \ln E P_{i, t} ; \gamma, c\right)+\mu_{i} \\
& \mu_{i}=\rho W \mu_{i}+e_{i}
\end{aligned}
$$

where $G(x)$ is a logistic smooth transition function form:

$$
G\left(W \ln E P_{i, t} ; \gamma, c\right)=\frac{1}{1+\exp \left[-\gamma\left(W \ln E P_{i, t}-c\right) / \sigma_{\mathrm{wx}}\right]}
$$

Different from the benchmark convergence model above, this convergence model takes spatial correlation effect and spatial smooth transition effect into consideration. Spatial correlation effect 
is measured by spatial correlation coefficient $\rho$, and the nonlinear function $G(W x)$ captures the nonlinearity. When the spatial smooth transition effect is not taken into consideration, namely $\delta_{0}=\delta_{1}=0$, the model is converted to be Spatial Error Model which can calculate the convergence rate under spatial correlation. After the spatial correlation is considered, the form of convergence parameter is similar to that of the benchmark convergence model, but the essence of convergence rate calculated by the former convergence parameter not only refers to the convergence per se, but also includes the electricity technological spillovers. When spatial correlation is not considered, namely $\rho=0$, the model is converted to be Spatial STAR Model, and in this situation, the converging parameter of urban electricity productivity is not a constant $\beta_{1}$, but it is $\beta_{1}+\delta_{1} G(W x)$, varying cross regions and ranging from $\beta_{1}$ to $\beta_{1}+\delta_{1}$, through smooth transition function $G(W x)$. It helps to depict the spatial regime switching and obtain local convergence rate by considering spatial heterogeneity. In this paper, we comprehensively analyze the convergence issue by considering both spatial effects, as the model in Formula (7).

Then, $\beta$ conditional convergence model of urban electricity productivity can also be constructed by introducing spatial correlation effect and spatial nonlinear effect through Spatial Error STAR Model as follows.

$$
\begin{aligned}
& \ln \left(\frac{E P_{i, t+T}}{E P_{i, t}}\right)=\beta_{0}+\beta_{1} \ln E P_{i, t}+\left(\delta_{0}+\delta_{1} \ln E P_{i, t}\right) G\left(W \ln E P_{i, t} ; \gamma, c\right)+\theta Z_{i, t}+\mu_{i,} \\
& \mu_{i}=\rho W \mu_{i}+e_{i}
\end{aligned}
$$

where $\mathrm{Z}$ is control variable, which contains the factors about urban economics development, including gross and structure characteristics of urban economics [19] and $G(x)$ is the same as above in Equation (8). In this paper, urban per capita income $Y$ and urban industrial structure IS are selected to measure gross and structure characteristics of urban economics respectively, namely $Z=(Y, I S)$.

\subsubsection{Estimating Method and Hypothetical Test for Spatial Error STAR Model}

In the model established above, it is needed to not only estimate the spatial correlation coefficient $\rho$, but also the coefficients, $\gamma$ and c, in nonlinear function $G(x)$. In this paper, Feasible Generalized Least-Squares Method (FGLS Method) can be a useful tool for estimation of the model [30]. The concrete steps of FGLS Method are as follow.

Step1 Use the data to make an initial estimate for spatial STAR model by Appropriate Nonlinear Least Squares Method and obtain the residual $\mu$ from the regression.

Step2 Substitute $\mu$ obtained from Step.1 into the likelihood function of Spatial Error Model. The likelihood function of Spatial Error Model performs as:

$$
L\left(\phi, \rho, \sigma^{2}\right)=-\frac{N}{2} \ln \left(\sigma^{2}\right)+\ln |I-\rho W|-\frac{1}{2 \sigma^{2}} \mu^{T} \mu
$$

where $\phi=(\beta, \delta, \gamma, c)$. Then maximize the likelihood function and obtain the estimate $\hat{\rho}$ for parameter $\rho$.

Step3 Apply Cochrane-Orcutt Transforming Method based on the estimation $\hat{\rho}$ and obtain the transformed variables.

$$
\begin{aligned}
& \widetilde{y}=(I-\hat{\rho} W) y \\
& \widetilde{X}=(I-\hat{\rho} W) X
\end{aligned}
$$

Then use the transformed variables $\widetilde{y}$ and $\widetilde{X}$ for regression.

Step4 Repeat the above steps with transformed variables of $y$ and $X$ until convergence.

Based on FGLS Method, it is effective to acquire the FGLS Estimation of Spatial Error STAR Model. The Application of Spatial Error STAR Model facilitates the construction of hypothetical test to examine the spatial effect, including spatial correlation effect and spatial nonlinear effect. In order to establish 
the hypothetical test, Taylor Expansion Method can be used to realize linear conversion of transition function and construct the LM statistics for testing spatial effect.

Firstly, approximate linear form of transition function $G(x)$ is derived from Taylor Expansion in $\gamma=0$ :

$$
\mathrm{G}=\frac{1}{2}-\frac{(W x-c)}{4 \sigma_{W X}} \gamma+(\gamma) \approx \lambda_{0}+\lambda_{1} W x
$$

where

$$
\lambda_{0}=\frac{\left(2 \sigma_{W x}-c \gamma\right)}{4 \sigma_{W x}}, \lambda_{1}=\frac{\gamma}{4 \sigma_{W x}}
$$

Then, the Spatial Error STAR model can be rewritten as,

$$
y=X \beta+X \delta \circ\left(\lambda_{0}+\lambda_{1} W X\right)+(1-\rho W)^{-1} \mu
$$

That is,

$$
\begin{aligned}
y & =X \beta+X \delta \circ \lambda_{0}+X \delta \circ \lambda_{1} W X+(1-\rho W)^{-1} \mu \\
& =T \xi+(1-\rho W)^{-1} \mu
\end{aligned}
$$

where $T=[X, X * W X], \xi=\left(\alpha^{\prime}, \varphi^{\prime}\right), \alpha=\beta+\lambda_{0}{ }^{\prime} \delta, \varphi=\lambda_{1}{ }^{\prime} \delta$

Then the $L M$ statistics can be established as follow:

$$
\begin{gathered}
L M_{\varphi=0 \mid \rho=0}=\frac{\mu^{T} T\left(T^{T} T\right)^{-1} T^{T} \mu}{\sigma^{2}} \sim \chi(k) \\
L M_{\varphi=0 \mid \rho \neq 0}=\frac{\widetilde{\mu}^{T} \widetilde{T}\left(\widetilde{T}^{T} \widetilde{T}\right)^{-1} \widetilde{T}^{T} \widetilde{\mu}}{\widetilde{\sigma}^{2}} \sim \chi(k) \\
L M_{\rho=0 \mid \varphi=0}=\frac{1}{\operatorname{tr}\left(\left(\mathrm{W}^{T}+\mathrm{W}\right) \mathrm{W}\right)}\left(\frac{\mu^{T} W \mu}{\sigma^{2}}\right)^{2} \sim \chi(1) \\
L M_{\rho=0 \mid \varphi \neq 0}=\frac{1}{\operatorname{tr}\left(\left(W^{T}+W\right) W\right)}\left(\frac{\widehat{\mu}^{T} W \widehat{\mu}}{\sigma^{2}}\right)^{2} \sim \chi(1) \\
L M_{\rho=\varphi=0}=\frac{\mu^{T} T\left(T^{T} T\right)^{-1} T^{T} \mu}{\sigma^{2}}+\frac{1}{\operatorname{tr}\left(\left(W^{T}+W\right) W\right)}\left(\frac{\mu^{T} W \mu}{\sigma^{2}}\right)^{2} \\
=L M_{\varphi=0 \mid \rho=0}+L M_{\rho=0 \mid \varphi=0} \sim \chi(k+1)
\end{gathered}
$$

where

$$
\mu=y-X \xi, \widetilde{\mathrm{T}}=(\mathrm{I}-\rho \mathrm{W}) \mathrm{T}, \widetilde{\mu}=(\mathrm{I}-\rho \mathrm{W}) \mu, \widehat{\mu}=y-T \beta,
$$

and $k$ is number of constraints for $\varphi=0$.

\subsection{Data}

Aiming at studying the convergence of urban electricity productivity in China, 261 representative cities are chosen as the research subject, and the time window of this study is from 1990 to 2011. The electricity consumption of these 261 cities chosen account for more than $90 \%$ of whole consumption in China, and these cities are located throughout the whole country from east to west, which manifests the research subject is sufficiently reflective of urban electricity productivity in China.

The description and source of data are introduced in this section. As mentioned above, we measure electricity productivity by the ratio of Gross Domestic Product (GDP) to Total Electricity Consumption, inverse of electricity intensity. In order to make agreement of statistical caliber, the data of GDP are transformed into the 1990 prices with price index. The indices of urban economy include Economic Development and Economic Structure. In this paper, we use per capita income to measure gross characteristic of urban economy and industrial structure as structural characteristic. 
The major source of the data used in this paper is CEI (China Economic Information) Net Statistics Database [31] and Urban Statistical Yearbook of China (1991-2012) [32]. Some missing data are supplemented from Statistical Yearbook of corresponding cities. The data collected have been further processed and the descriptive statistical analysis of the variables is listed in Table 1.

Table 1. Descriptive Statistical Analysis of the Variables.

\begin{tabular}{cccccc}
\hline Variable & Index & Average & Maximum & Minimum & St.Dev \\
\hline $\begin{array}{c}\text { Electricity } \\
\text { Productivity } \\
\text { (EP) }\end{array}$ & $\begin{array}{c}\text { The ratio of Gross Domestic Product } \\
\text { to Total Electricity Consumption } \\
\text { (million kilowatt hour/million Yuan) }\end{array}$ & 7.805 & 72.284 & 0.498 & 6.434 \\
\hline $\begin{array}{c}\text { Economic } \\
\text { Development } \\
(Y)\end{array}$ & Per capita income (Yuan) & 2370.815 & $17,637.241$ & 431.571 & 1742.487 \\
\hline $\begin{array}{c}\text { Industrial } \\
\text { Structure } \\
\text { (IS) }\end{array}$ & $\begin{array}{c}\text { The proportion of the added value of } \\
\text { Secondary Industry in GDP (\%) }\end{array}$ & 0.416 & 0.911 & 0.065 & 0.179 \\
\hline
\end{tabular}

Resource: CEINet Statistics Database [31], Urban Statistical Yearbook of China [32].

\section{Result and Discussion}

\subsection{The Absolute Convergence of Electricity Productivity and Its Spatial Effect}

As mentioned above, previous literature seldom considers spatial regime switching. To explore how spatial regime switching affects the convergence of urban electricity productivity, it is initially necessary to define the spatial weighted matrix. In this paper, the spatial weighted matrix $\mathrm{W}$ is constructed through the geographical distance among cities:

$$
w_{i j}=\left\{\begin{array}{cc}
1 / d_{i j^{\prime}}^{2} & i \neq j \\
0, & i=j
\end{array}\right.
$$

Then based on the spatial structure $W$, we define spatial lag term $W X=W \times \ln E P_{1990}$, and divide the sample into three spatial regimes based on the quantile of variable $W X$, and plot the convergence of these sub-samples in Figure 1. As depicted in Figure 1, it is evident that a significant negative correlation between the change of electricity productivity and initial electricity productivity exists in all three spatial regimes divided by quantile of $W x$, which illustrates that convergence trend would be robust with spatial regimes switching while the convergence rate of urban electricity productivity will vary under different spatial regimes. We can also observe that the change of convergence rate with spatial regimes switching is not systematic. The change is rapid from Regime (A) to Regime (B) while it is moderate from Regime (B) to Regime (C), which shows that the change with spatial regime switching is nonlinear. Thus, it is exhibited intuitively that the nonlinear spatial effect caused by spatial regime switching will affect the convergence of urban electricity productivity.

Firstly, the convergence model is estimated by traditional OLS method. Then Spatial STAR model and Spatial Error Model are applied to estimate the convergence model, to measure the spatial correlation effect and spatial smooth transition effect. Finally, Spatial Error STAR Model is utilized, taking the spatial correlation effect and spatial smooth transition effect into consideration comprehensively. Based on the estimates, the convergence rate could be calculated by follows:

$$
C R=100 * \frac{[-\ln (1+\beta)]}{T}
$$




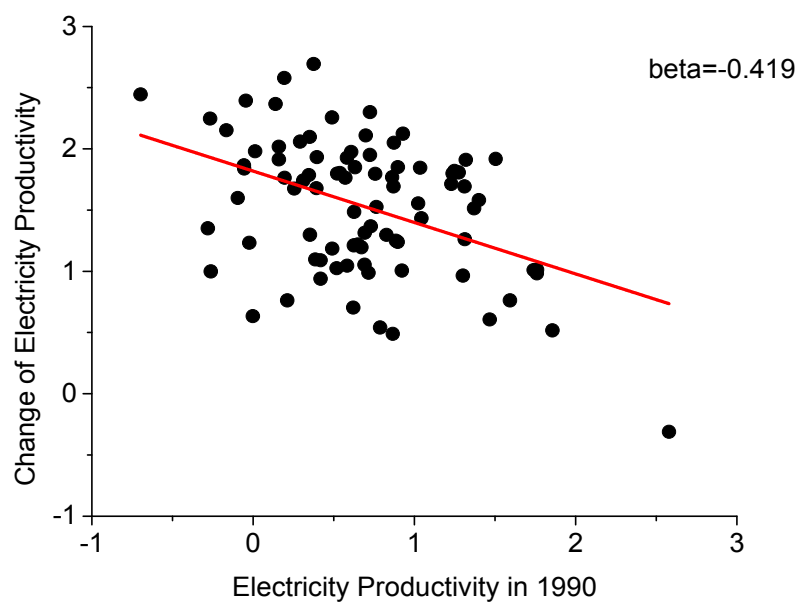

(A)

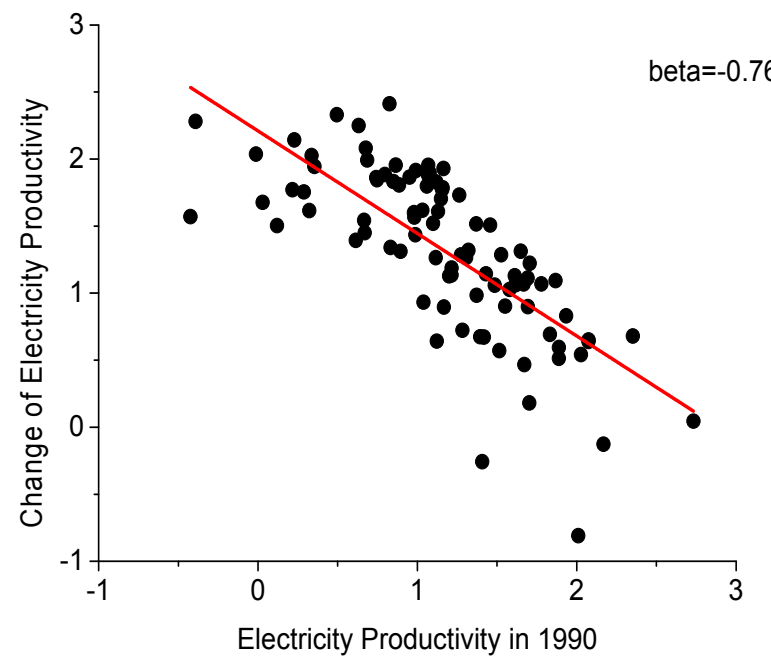

(B)

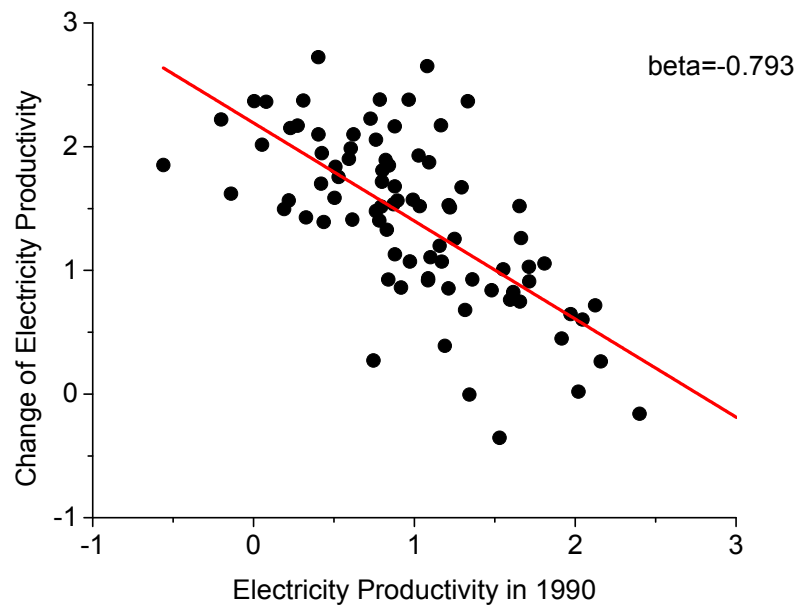

(C)

Figure 1. Correlation of change of Electricity Productivity (Y) and Electricity Productivity in 1990 (X) (1990-2011): (A) $\min (w x)<w x<$ quantile ( $w x, 0.33)$; (B) quantile ( $w x, 0.33)<w x<$ quantile ( $w x, 0.66)$; (C) quantile $(w x, 0.66)<w x<\max (w x)$.

Table 2 reports estimates of absolute convergence model by four different methods. According to Table 2, the value of $\beta$ in the regression model is estimated to be negative by all methods, 
denoting that absolute convergence of urban electricity productivity exists from 1990 to 2011 in China. The parameters estimated by these four methods are different and they cannot be compared directly. The value of $\beta$ estimated by OLS model and Spatial Error Model are fixed values, -0.654 and -0.667 , which can be applied to obtain constant convergence rates based on Formula (22), while the ones estimated by Spatial STAR Model and Spatial Error STAR Model, which is $\beta_{1}+\delta_{1} G(W x)$, vary across cities which can capture the heterogeneity caused by spatial regime switching and their values range in $[-0.791,-0.438]$ and $[-0.786,-0.401]$, respectively. Figure 2 exhibits the smooth transition effect caused by spatial regime switching. Different from the fixed values obtained by OLS and Spatial Error Model, the unbalanced convergence characteristic can be revealed by the heterogeneous convergence rates and more details about regional variation of convergence will be discussed in Section 3.3. To make a comparison, we calculated heterogeneous convergence rates from the parameters of these two models and obtain their average value. The corresponding results are listed in the last row of Table 2. It is mentionable that the values of parameters estimated by Spatial STAR Model and Spatial Error STAR Model have not converted to be positive, exhibiting the significant convergence characteristic, and it also corresponds to the explanation in Figure 1.

Table 2. Estimate of Electricity Efficiency Absolute Convergence Model: 1990-2011.

\begin{tabular}{|c|c|c|c|c|}
\hline Parameter & OLS & Spatial STAR Model & Spatial Error Model & Spatial Error STAR Model \\
\hline$\beta_{0}$ & $\begin{array}{l}2.038^{* * *} \\
(37.99)\end{array}$ & $\begin{array}{l}1.796^{* * *} \\
(15.492)\end{array}$ & $\begin{array}{l}2.049^{* * *} \\
(36.142)\end{array}$ & $\begin{array}{l}1.765^{* * *} \\
(12.892)\end{array}$ \\
\hline$\beta_{1}$ & $\begin{array}{l}-0.654^{* * *} \\
(-13.99)\end{array}$ & $\begin{array}{l}-0.438^{* * *} \\
(-3.686)\end{array}$ & $\begin{array}{l}-0.667^{* * *} \\
(-14.09)\end{array}$ & $\begin{array}{l}-0.401^{* * *} \\
(-2.898)\end{array}$ \\
\hline$\delta_{0}$ & & $\begin{array}{c}0.438^{* * * *} \\
(2.733)\end{array}$ & & $\begin{array}{c}0.4511^{* * *} \\
(2.601)\end{array}$ \\
\hline$\delta_{1}$ & & $\begin{array}{l}-0.353^{* * *} \\
(2.377)\end{array}$ & & $\begin{array}{l}-0.385^{* * *} \\
(-2.362)\end{array}$ \\
\hline$\gamma$ & & $\begin{array}{c}6.635 \\
(0.813)\end{array}$ & & $\begin{array}{l}7.030 \\
(0.750)\end{array}$ \\
\hline c & & $\begin{array}{c}0.740 * * * \\
(6.492)\end{array}$ & & $\begin{array}{l}0.693 * * * \\
(-6.508)\end{array}$ \\
\hline$\rho$ & & & $\begin{array}{l}0.141^{* *} \\
(4.621)\end{array}$ & $\begin{array}{l}0.121^{* *} \\
(1.969)\end{array}$ \\
\hline $\begin{array}{l}\text { Convergence } \\
\text { rate }(\%)\end{array}$ & $\begin{array}{l}5.054 \\
\text { (Fixed) }\end{array}$ & $\begin{array}{c}5.664 \\
\text { (Average) }\end{array}$ & $\begin{array}{l}5.236 \\
\text { (Fixed) }\end{array}$ & $\begin{array}{c}5.676 \\
\text { (Average) }\end{array}$ \\
\hline
\end{tabular}

Note: ${ }^{* *}$ and ${ }^{* *}$ mean that the estimate of parameter is significant at the level of $0.01,0.05$ and 0.1 , respectively, and the numbers in parentheses are the values of T Statistics.

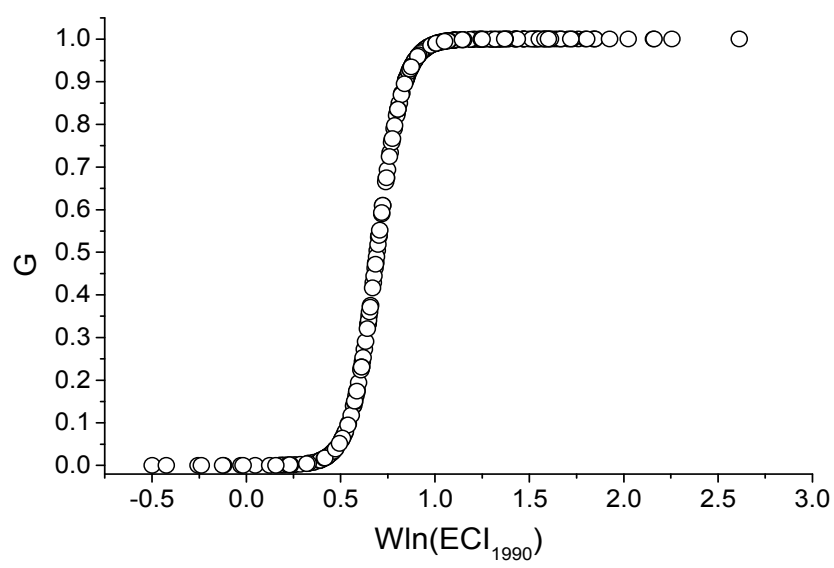

Figure 2. Curve of Smooth Transition Function. 
Then, we can analyze the spatial effect deeply and some conclusions can be summarized as follow.

(1) The result of SEM Model reports that the spatial correlation effect across cities in the convergence of electricity productivity is significant ( $\rho=0.141$ and it is statistically significant at $5 \%$ level). Compared with the estimate of OLS Model, convergence rate calculated by SEM Model is $5.236 \%$, higher than the $5.054 \%$ by OLS model. It elucidates that the convergence rate calculated by traditional model is underestimated, because the spatial correlation effect has been ignored, which can affect the convergence of electricity productivity by technology diffusion and energy flowing cross cities. The result also shows that the interaction cross-city interaction benefits the development of urban electricity productivity.

(2) According to estimate of Spatial STAR Model, the convergence rate is $5.664 \%$ if the spatial smooth transition effect is considered, higher than the one by OLS Model, even higher than the one by SEM Model, which depicts that spatial smooth transition effect is stronger than spatial correlation effect. Meanwhile, with the increasing of electricity productivity of surrounding cities, the convergence rate of urban electricity productivity is affected by spatial smooth transition, depicting that the enhancing of spatial regime variable $W x$ can play a positive role in convergence of electricity productivity. If the city is initially surrounded by the circumstance with high-level electricity productivity, its implementation effect of energy-saving target will be affected and more attention will be paid for improvement of urban electricity productivity. This kind of spatial effect mainly derives from the competition among urban governments, which is called catch-up effect.

(3) It is worth mentioning that if the spatial correlation effect and spatial smooth transition effect are simultaneously taken into consideration, using Spatial Error STAR Model to estimate the convergence of urban electricity productivity, the convergence rate is $5.676 \%$, higher than the estimation calculated by other three methods. It is depicted that these two kinds of spatial effect both enhance the convergence of urban electricity productivity, and spatial smooth transition effect play the dominant role. Therefore, the convergence rate calculated by Spatial Error STAR Model is more reliable than other methods, and the convergence rate will be underestimated if spatial effect is neglected.

\subsection{The LM Test for Spatial Effect}

Based on the LM Test proposed above, the spatial effect in the converging process of electricity productivity can be examined, aiming to select the appropriate model for analysis. The result of LM Test is listed in Table 3.

Table 3. Results of LM Test.

\begin{tabular}{ccc}
\hline No. & Test & Statistics Value \\
\hline 1 & $\operatorname{LM}_{\varphi=0 \mid \rho=0}$ & $7.9988^{* *}$ \\
2 & $\operatorname{LM}_{\varphi=0 \mid \rho \neq 0}$ & $6.3872^{* *}$ \\
3 & $\operatorname{LM}_{\rho=0 \mid \varphi=0}$ & $4.9125^{* *}$ \\
4 & $\operatorname{LM}_{\rho=0 \mid \varphi \neq 0}$ & $3.3518^{*}$ \\
5 & $\operatorname{LM}_{\rho=0, \varphi=0}^{* * *}$ & $12.9113^{* *}$ \\
\hline
\end{tabular}

Note: ${ }^{* * *}, * *$, and $*$ mean that the estimate of parameter is significant at the level of $0.01,0.05$ and 0.1 , respectively.

According to Table 3 , Test 1 and Test 2 denote that whether $\rho=0$ or $\rho \neq 0, \varphi$ significantly is unequal to 0 , namely that whether the spatial correlation effect exists, the spatial smooth transition effect exists significantly in convergence of electricity productivity. Test 3 and Test 4 denote that whether $\varphi=0$ or $\varphi \neq 0, \rho$ is unequal to 0 significantly, namely that whether the spatial smooth transition effect exists, the spatial correlation effect exists significantly in convergence of electricity productivity. Test 5 rejects the hypothesis that the two types of spatial effect does not exist simultaneously, namely that $\varphi$ and $\rho$ are unable to be 0 simultaneously. 
Synthesizing the results of LM Test, it is concluded that the spatial correlation effect and spatial smooth transition effect exist in convergence of electricity productivity statistically at $5 \%$ level, which denotes that it is defective to use OLS to analyze the convergence of electricity productivity. It is also insufficient to take only spatial correlation or spatial regime switching into consideration. Therefore, the result estimated by Spatial Error STAR Model is more in line with reality.

\subsection{The Stage Characteristics of Electricity Productivity Convergence}

The electricity market reformation in 2002 exerts an immense effect on electricity consumption in China. The key elements of this reformation include separation of power plants from the power grids, separation of the main business of Electricity Grid from the auxiliary one, establishment of regional electricity market, solving the imbalance between supply and demand in electricity market, and optimizing the formation of electricity price. This reformation of electricity system, which aims to break up monopoly and realize the optimization of regional electricity resource allocation, is a revolutionary change because it is a symbol that China starts to concentrates on electricity price formation mechanism. The reformation on electricity not only affects the allocation efficiency of regional electricity but also influences spillover of electricity technology. Thus, the convergence of electricity productivity can be also affected by this reformation and shows different stage characteristics.

To analyze the stage characteristics of electricity productivity convergence, the time window of this paper can be divided into two stages with 2002 as the dividing line, namely 1990-2001 and 2002-2011. Then, the convergence model of urban electricity productivity during these two stages can be estimated and compared.

Firstly, the convergence model of the former period (1990-2001) is estimated by OLS, Spatial STAR Model, Spatial Error Model, and Spatial Error STAR Model, separately, and the results are listed in Table 4. According to Table 4, during former period before reformation, the convergence of urban electricity productivity is significant, while the convergence rate is evidently lower than the whole period. Next, aiming at obtaining further comparison, the convergence model during later period (2002-2011) is similarly estimated and results are listed in Table 5.From results in Table 5, convergence rate of urban electricity productivity significantly increases during latter period after electricity reformation.

Table 4. Estimate of Electricity Productivity Absolute Convergence Model: 1990-2001.

\begin{tabular}{|c|c|c|c|c|}
\hline Parameter & OLS & Spatial STAR Model & Spatial Error Model & Spatial Error STAR Model \\
\hline$\beta_{0}$ & $\begin{array}{l}1.3289^{* * *} \\
(27.403)\end{array}$ & $\begin{array}{c}1.1507^{* * *} \\
(8.195)\end{array}$ & $\begin{array}{l}1.3364^{* * *} \\
(26.430)\end{array}$ & $\begin{array}{c}1.1526^{* * *} \\
(7.466)\end{array}$ \\
\hline$\beta_{1}$ & $\begin{array}{c}-0.3966^{* * *} \\
(-9.386)\end{array}$ & $\begin{array}{c}-0.2660^{* * *} \\
(-2.030)\end{array}$ & $\begin{array}{c}-0.4033^{* * *} \\
(-9.432)\end{array}$ & $\begin{array}{c}-0.27111^{* *} \\
(-1.951)\end{array}$ \\
\hline$\delta_{0}$ & & $\begin{array}{c}0.3028^{* *} \\
(1.601)\end{array}$ & & $\begin{array}{c}0.2930 * * \\
(1.466)\end{array}$ \\
\hline$\delta_{1}$ & & $\begin{array}{l}-0.2121 * \\
(-1.293)\end{array}$ & & $\begin{array}{l}-0.2013^{*} \\
(-1.182)\end{array}$ \\
\hline$\gamma$ & & $\begin{array}{l}4.0312 \\
(0.627)\end{array}$ & & $\begin{array}{c}4.0449 \\
(0.56395)\end{array}$ \\
\hline c & & $\begin{array}{c}0.6817^{* * *} \\
(3.102)\end{array}$ & & $\begin{array}{c}0.6659^{* * *} \\
(2.807)\end{array}$ \\
\hline$\rho$ & & & $\begin{array}{c}0.10385^{* * *} \\
(2.450)\end{array}$ & $\begin{array}{c}0.0746^{* *} \\
(1.579)\end{array}$ \\
\hline $\begin{array}{l}\text { Convergence } \\
\text { rate }(\%)\end{array}$ & $\begin{array}{c}4.584 \\
\text { (Fixed) }\end{array}$ & $\begin{array}{c}4.893 \\
\text { (Average) }\end{array}$ & $\begin{array}{c}4.694 \\
\text { (Fixed) }\end{array}$ & $\begin{array}{c}4.901 \\
\text { (Average) }\end{array}$ \\
\hline
\end{tabular}

Note: ${ }^{* * *}, * *$, and ${ }^{*}$ mean that the estimate of parameter is significant at the level of $0.01,0.05$ and 0.1 respectively, and the number in parentheses are the values of T Statistics. 
Table 5. Estimate of Electricity Productivity Absolute Convergence Model: 2001-2011.

\begin{tabular}{|c|c|c|c|c|}
\hline Parameter & OLS & Spatial STAR Model & Spatial Error Model & Spatial Error STAR Model \\
\hline$\beta_{0}$ & $\begin{array}{l}1.3338^{* * *} \\
(14.750)\end{array}$ & $\begin{array}{l}1.1508^{* * *} \\
(8.176)\end{array}$ & $\begin{array}{l}1.3478^{* * *} \\
(14.759)\end{array}$ & $\begin{array}{c}1.1424^{* * *} \\
(7.992)\end{array}$ \\
\hline$\beta_{1}$ & $\begin{array}{c}-0.4571^{* * *} \\
(10.060)\end{array}$ & $\begin{array}{c}-0.3967^{* * *} \\
(-5.102)\end{array}$ & $\begin{array}{c}-0.4647^{* * *} \\
(-10.178)\end{array}$ & $\begin{array}{c}-0.3927^{* * *} \\
(-5.110)\end{array}$ \\
\hline$\delta_{0}$ & & $\begin{array}{c}0.4019^{* * *} \\
(1.986)\end{array}$ & & $\begin{array}{c}0.4346^{* * *} \\
(2.110)\end{array}$ \\
\hline$\delta_{1}$ & & $\begin{array}{l}-0.1451 * \\
(-1.400)\end{array}$ & & $\begin{array}{l}-0.1604^{* *} \\
(-1.546)\end{array}$ \\
\hline$\gamma$ & & $\begin{array}{l}11.5147 \\
(0.373)\end{array}$ & & $\begin{array}{c}11.4114 \\
(0.373)\end{array}$ \\
\hline c & & $\begin{array}{l}1.8180 * * * \\
(18.099)\end{array}$ & & $\begin{array}{l}1.8321 * * * \\
(20.184)\end{array}$ \\
\hline$\rho$ & & & $\begin{array}{l}0.0557 \\
(0.668)\end{array}$ & $\begin{array}{l}0.0581 \\
(0.711)\end{array}$ \\
\hline $\begin{array}{c}\text { Convergence } \\
\text { rate }(\%)\end{array}$ & $\begin{array}{l}6.108 \\
\text { (Fixed) }\end{array}$ & $\begin{array}{c}6.743 \\
\text { (Average) }\end{array}$ & $\begin{array}{c}6.249 \\
\text { (Fixed) }\end{array}$ & $\begin{array}{c}6.820 \\
\text { (Average) }\end{array}$ \\
\hline
\end{tabular}

Note: ${ }^{* * *},{ }^{* *}$, and ${ }^{*}$ mean that the estimate of parameter is significant at the level of $0.01,0.05$ and 0.1 respectively, and the number in parentheses are the values of T Statistics.

As mentioned above, the overall convergence rate during 1990-2011 is $5.68 \%$. It is known from comparison that the convergence rate during former period is $4.90 \%$, lower than overall convergence rate, while the convergence rate during latter period is $6.82 \%$, higher than overall convergence rate. The main reasons can be summarized as three aspects. Firstly, in former period, administrative examination dominated in electricity price forming mechanism, leading to a vast distortion of urban electricity price, and the adjusting effect of market was not fully revealed, resulting in low-level resource allocation efficiency in electricity market. Secondly, the relatively laggard electricity technology in electricity-intensive industry was bad for technology diffusion cross regions, hindering the co-improvement of urban electricity productivity. Lastly, the electricity system with low-level marketization could not benefit the introduction of foreign investment and advanced electricity technology and management. Therefore, before 2002, the electricity productivity in China remains a convergence to some extent, but the convergence rate maintains a relatively lower level.

As the electricity market reformation deepens continuously, the market formation mechanism of electricity price is facilitated by the implementation of the policy that power plants are separated from the power grids and the improvement of electricity price bidding system. Then, compared with the situation that monopoly electricity price dominated during the past decade, the price in the latter period can to be a correct sign of the supply and demand in electricity market, which promotes the allocation efficiency in electricity market cross regions in China.

The increase of the marketization level can motivate economic agents invest more in research and development of electricity-saving technology in some electricity-intensive industries and contribute to the utilization of new energy resources [33]. During the latter period, the increase of sales of thermal power slows down and the alternative energy resources, such as hydropower and nuclear power, emerge in electricity market, effectively facilitating the convergence of urban electricity productivity.

Meanwhile, improvement of electricity market system can stimulate the introduction of foreign capital in electricity market, bringing in advanced technology and experience, benefitting the international technology spillover. Through technology spillover effect, the convergence of urban electricity productivity can be promoted. For the foregoing reasons, a significant increase on convergence rate appears during the period after electricity market reformation (2002-2011).

According to Tables 4 and 5, the influence of spatial correlation effect and spatial smooth transition effect can be demonstrated obviously. If such spatial influence is neglected, the convergence rate will 
be underestimated. Then, coefficients of spatial lag term for two different periods are both smaller than the one of whole period, which demonstrates that the spatial correlation effect can make an long-term influence on the convergence of urban electricity productivity, while it is weaker in the short-term.

It is also found that the influences of spatial smooth transition effect during two periods are different. The spatial smooth transition effect in the later period is higher than the former and its influence is also higher than the overall period. It is interpreted that, after 2002, with electricity market system improving and stricter monitoring index system of energy conservation and emission reduction on city government constructed under advocacy of sustainable development, the competition among city governments in implementation of electricity-saving policy gradually increases, leading to a higher enhancing influence on convergence of urban electricity productivity.

Considering the regional unbalance of China's urban development, the regional variation of electricity productivity convergence is an issue worthy of exploration. According to the realities of economics development and electricity marketization, the selected cities can be divided into three regions, denoted as Region I, Region II and Region III. Region I includes the cities of eastern area, and Region II includes the cities of central area, and the cities of western area and northeastern area belong to Region III. The stage characteristic of urban electricity productivity convergence in every region is shown in Figure 3.

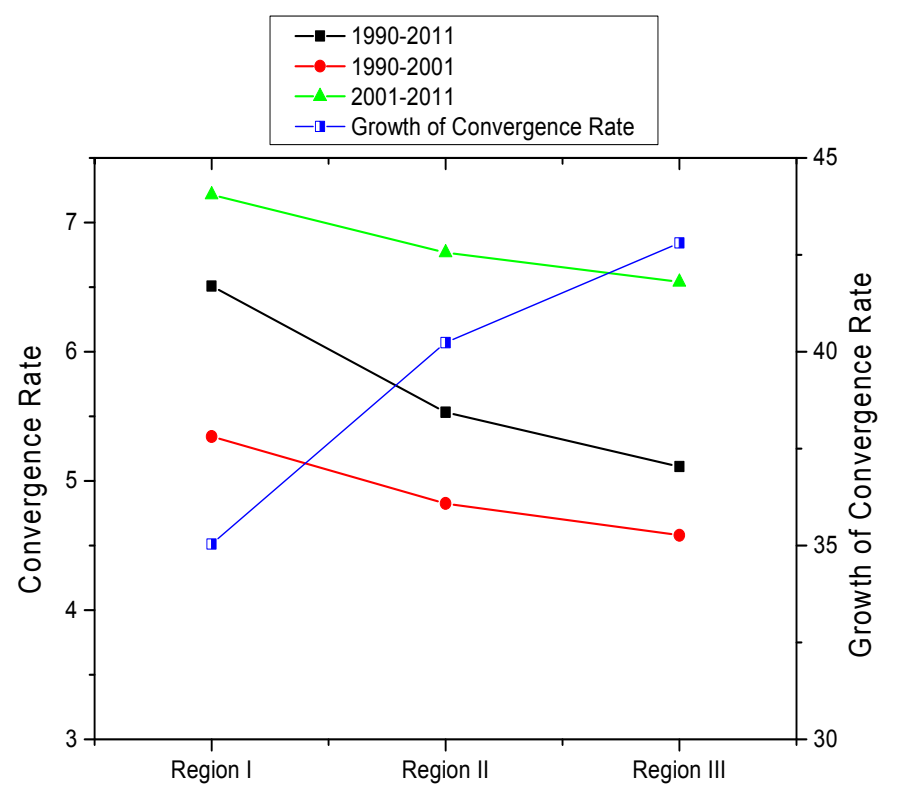

Figure 3. Convergence Rate in Different Regions.

As depicted in Figure 3, convergence rate is decreasing progressively from Region I to Region III, which manifests that the convergence of urban electricity productivity in eastern area is best realized, followed by central area, while the converging level in western and northeastern area is relatively lower, corresponding to the contemporary development of region electrical technology in China. However, it is worth mentioning that the growth rate of convergence rate in Region III is maximum among three regions and the growth rate decreases from Region III to Region I, which indicates that the growth rate of convergence rate of cities in Region III benefits best from electricity market reformation, and it is necessary to accelerate the reform of electricity market in this region, further narrowing the disparity of urban electricity productivity among regions.

\subsection{The Conditional Convergence of Electricity Productivity Considering Economics Variation}

The analysis above examines the existence of absolute convergence of urban electricity productivity in China and it has different characteristics in different periods. Meanwhile, results 
above show that spatial correlation effect and spatial smooth transition effect contribute significantly in absolute convergence of urban electricity productivity. However, the convergence of urban electricity productivity is inevitably affected by urban economy in theory, which is called conditional convergence of urban electricity productivity. To further study the influence of urban economics on convergence of electricity productivity, a conditional convergence model of urban electricity productivity, considering urban economics development and urban industrial structure, is constructed.

Based on the model constructed, OLS, Spatial STAR model, Spatial Error Model and Spatial error STAR model are applied in estimation of parameters. The empirical results of conditional convergence model are listed in Table 6.

Table 6. Estimate of Electricity Productivity Conditional Convergence Model: 1990-2011.

\begin{tabular}{|c|c|c|c|c|}
\hline Parameter & OLS & Spatial STAR Model & Spatial Error Model & Spatial Error STAR Model \\
\hline$\beta_{0}$ & $\begin{array}{c}1.3842^{* * *} \\
(3.117)\end{array}$ & $\begin{array}{c}1.1767^{* * *} \\
(2.57)\end{array}$ & $\begin{array}{c}1.1123^{* * *} \\
(2.433)\end{array}$ & $\begin{array}{c}0.8668^{* *} \\
(1.842)\end{array}$ \\
\hline$\beta_{1}$ & $\begin{array}{c}-0.6461^{* * *} \\
(-11.582)\end{array}$ & $\begin{array}{c}-0.3994^{* * *} \\
(-3.208)\end{array}$ & $\begin{array}{c}-0.6664^{* * *} \\
(-12.089)\end{array}$ & $\begin{array}{c}-0.3506^{* * *} \\
(-2.237)\end{array}$ \\
\hline$\delta_{0}$ & & $\begin{array}{c}0.4496^{* * *} \\
(2.786)\end{array}$ & & $\begin{array}{c}0.4591^{* * *} \\
(2.491)\end{array}$ \\
\hline$\delta_{1}$ & & $\begin{array}{c}-0.3781^{* * *} \\
(-2.494)\end{array}$ & & $\begin{array}{c}-0.4258^{* * *} \\
(-2.404)\end{array}$ \\
\hline$\gamma$ & & $\begin{array}{l}6.4852 \\
(0.853)\end{array}$ & & $\begin{array}{l}6.4830 \\
(0.799)\end{array}$ \\
\hline c & & $\begin{array}{c}0.7463 * * * \\
(6.587)\end{array}$ & & $\begin{array}{c}0.6805^{* * *} \\
(6.238)\end{array}$ \\
\hline$\rho$ & & & $\begin{array}{c}0.1689^{* * *} \\
(6.277)\end{array}$ & $\begin{array}{c}0.1490^{* * *} \\
(2.786)\end{array}$ \\
\hline$\theta_{1}$ & $\begin{array}{l}0.0868^{*} \\
(1.219)\end{array}$ & $\begin{array}{l}0.0712 \\
(0.989)\end{array}$ & $\begin{array}{l}0.1338^{* *} \\
(1.842)\end{array}$ & $\begin{array}{c}0.1179 * * \\
(1.608)\end{array}$ \\
\hline$\theta_{2}$ & $\begin{array}{l}-0.0243 \\
(-0.086)\end{array}$ & $\begin{array}{l}0.0991 \\
(0.352)\end{array}$ & $\begin{array}{l}-0.1490 \\
(-0.530)\end{array}$ & $\begin{array}{l}-0.0436 \\
(-0.154)\end{array}$ \\
\hline $\begin{array}{l}\text { Convergence } \\
\text { rate }(\%)\end{array}$ & $\begin{array}{l}4.945 \\
\text { (Fixed) }\end{array}$ & $\begin{array}{c}5.329 \\
\text { (Average) }\end{array}$ & $\begin{array}{l}5.228 \\
\text { (Fixed) }\end{array}$ & $\begin{array}{c}5.439 \\
\text { (Average) }\end{array}$ \\
\hline
\end{tabular}

Note: ${ }^{* * *}, * *$ and $*$ mean that the estimate of parameter is significant at the level of $0.01,0.05$ and 0.1 respectively, and the number in parentheses are the values of T Statistics.

The results in Table 6 indicate that urban economic factors, including urban economics development and urban industrial structure, also affect the convergence of urban electricity productivity. Based on the results, main conclusions can be summarized as follow.

(1) The conditional convergence significantly exists in China during the sample period (1990-2011). Compared with results calculated above, the conditional convergence rate is $5.439 \%$, lower than the absolute convergence rate $5.676 \%$. This conclusion is also proved by other methods. The reason why urban economy does not significantly play a positive role in convergence of electricity productivity is that the level of initial endowment of urban economics development is relatively low and the high disparity of urban development also hinders the convergence of electricity productivity.

(2) Although the urban economic development has a positive effect on the increase of the urban electricity productivity, urban industrial structure shows an opposite effect. The cities with low growth rate on electricity productivity are mainly the ones with higher proportion of secondary industry, such as electrolytic aluminum industry, calcium carbide industry, steel industry, cement industry and so on. These electricity-intensive industries induce a large amount of electricity demand and the demand is rigid, which results in Path Dependence Effect in electricity demand, 
harmful to the growth of urban electricity productivity. Therefore, to accelerating the collaborative optimization of urban electricity productivity, it is vital to realize the optimization of urban industrial structure.

(3) Under the analysis framework of conditional convergence model, the influences of spatial correlation effect and spatial smooth transition effect both play a vital role to increase the convergence rate of urban electricity productivity. Compared with spatial correlation effect, spatial smooth transition effect exhibits a larger influence to promote the convergence.

Besides, urban economy exhibits different influence on electricity productivity convergence in different regions. As shown in Figure 4, conditional convergence rates in three regions are lower than the absolute convergence rate in these regions respectively. The disparities between absolute convergence rate and conditional convergence rate of different regions are also shown in Figure 4 . It is obvious that the gap between absolute convergence rate and conditional convergence rate in Region III is larger than two other regions, and the conditional convergence rate in Region III is 0.25 percent lower than corresponding absolute convergence rate, which manifests that the economy of western area and northeastern area exert a larger negative effect on electricity productivity convergence in these regions. The main reason for this phenomenon is relatively low level of economic development and unreasonable industrial structure in Region III. In Region III, the electricity-intensive and low value-added industries occupy the great proportion in the urban industry, against the optimization of urban electricity productivity. The relatively remote geographic locations of cities in Region III also inhibit the spillover effect of electricity technology among cities and it also impedes the convergence in this region. To improve the convergence in this region and accelerate the coordinate development of urban electricity productivity, it is important to promote rationalization of industry structure and appropriately reduce the proportion of electricity-intensive and low value-added industries. Meanwhile, strengthening the communication between backward cities and well-developed cities, by mean of national strategic project like Transmission of Power in West to East, is also an effective way to facilitate the convergence of urban electricity productivity, realizing the complementation of comparative advantages among different regions.

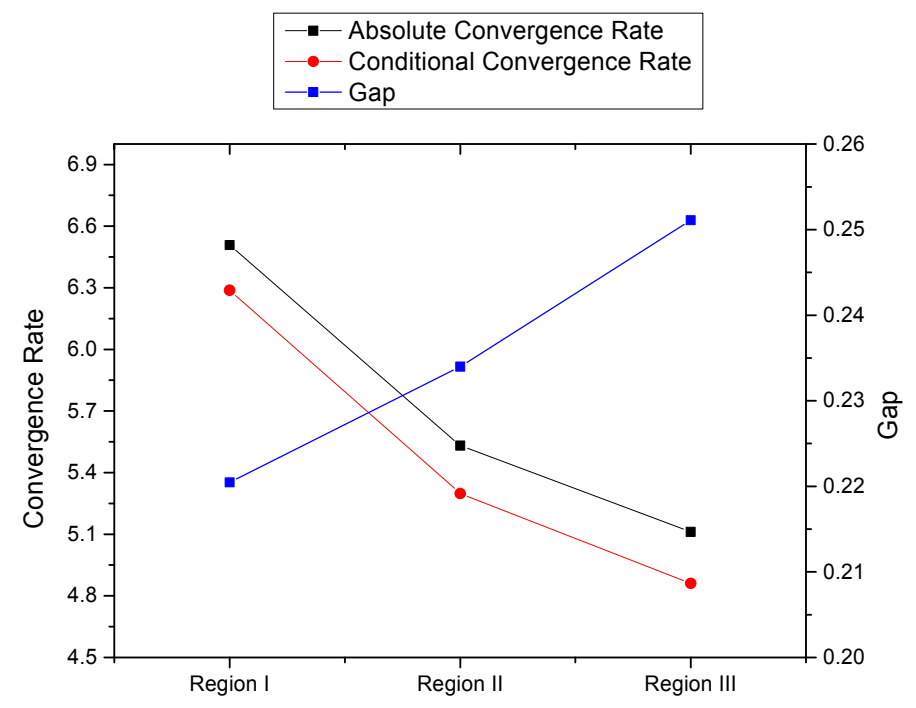

Figure 4. Absolute and Conditional Convergence Rate in Different Regions.

\section{Conclusions and Policy Implications}

The convergence of urban electricity productivity highlights the remarkable achievements in implementation of energy-saving and carbon emission reduction policy in China, and the researches on convergence of urban electricity productivity can facilitate the policy making for coordinating 
optimization of urban electricity utilization. However, ignorance of spatial effect may lead to an inaccuracy in estimation of electricity productivity convergence, it will not be useful in dealing with the electricity problems and will cause distorted analysis on the energy problems and misguided policy making. This study analyzes the convergence of urban electricity productivity among majority of cities in China with consideration of spatial correlation effect and spatial smooth transition effect and it also tests for the existence of spatial effect in convergence of electricity productivity. With the detailed analysis above, we can get some major conclusions as follows.

(1) There exists significant absolute convergence of urban electricity productivity in China. Spatial effect plays an important role to promote the convergence, especially spatial nonlinear smooth transition effect, which mainly derives from the competition effect among city governments for realizing the goal of energy-saving and carbon emission reduction. The spatial effect should not be ignored in research on convergence of urban electricity productivity; otherwise, it will under estimate the convergence rate.

(2) Since the electricity market reformation in 2002, significant stage characteristics appear in convergence of urban electricity productivity. Before 2002, the convergence rate, $4.90 \%$, is obviously lower than the one during the whole sample period $5.68 \%$, because of low marketization in electricity market and low level of urban electricity technology, while, after electricity market reformation, the convergence rate $6.82 \%$, enhances to large extent with the improvement of electricity marketization and the cooperation among cities for promoting electricity technology. It is higher than the convergence rate before 2002, and also higher than overall convergence rate. Meanwhile, spatial effect plays an important role during both periods, especially during the period after 2002. The spatial smooth transition effect strengths after 2002 because the competition effect among cities has been boost up with marketization in electricity market and stricter regulation on energy conservation.

(3) The urban economy also affects the convergence of urban electricity productivity, while it does not promote the convergence rate during the sample period. As the results shown, the conditional convergence rate is lower than absolute convergence rate. The main reason is that urban industrial structure shows an opposite effect in convergence of electricity productivity, especially in some cities in western and northeastern area with higher proportion of secondary industry. The rigid electricity demand in these cities caused by electricity-intensive industries induces Path Dependence Effect in electricity demand, harmful to the increasing of urban electricity productivity.

Based on the empirical analysis and major conclusions above, this paper puts forward some implications for policy makers in China on how to improve electricity productivity and realize the optimization of electricity utilization among different cities in China.

The first policy implication derived from this study is that the spatial effect should be taken into consideration for policy maker to realize the coordination of urban electricity utilization. From this perspective, it is necessary to strengthen the cooperation among cities in research and development on electricity technology, promoting the technology spillover effect across cities and then facilitating the urban electricity productivity convergence. In addition, it is essential to moderately strengthen competition among city government in implementation of low carbon policy by improving the evaluation of government in low carbon development and designing scientific supervision and punishing mechanism.

Secondly, to promote urban electricity productivity convergence and realize narrowing the gap of electricity utilization among cities, it is an effective way to accelerate the reform of electricity marketization, improving regulation function of electricity price on the electricity market and realizing the optimization of Chinese electricity structure to promote electricity productivity in current circumstance that new energy economy is developing. 
Finally, it is also significant to accelerate transforming the pattern of urban economics development, especially the cities in west and northeastern area. On the one hand, these cities should promote intensive mode of economic development, and gradually eliminate the electricity-intensive and low value-added industries, optimizing industrial structure to improve electricity productivity and facilitate the convergence. On the other hand, it is essential to promote energy-saving awareness of general public, especially industrial producers, leading low-carbon production mode to be formed in these electricity-intensive organizations through enhancing the energy-saving awareness, ultimately promoting the sustainability of urban economy.

Acknowledgments: This paper is supported by National Social Science Foundation of China (Grant No. 14ZDA062), Humanities and Social Science Research Foundation of Ministry of Education (Grant No.14JDGC012) and National Natural Science Foundation of China (Grant No. 71601148).

Author Contributions: Ming Luo constructed econometric models and performed all calculations. Ruguo Fan proposed research ideas, analyzed research results and offered policy suggestions. Yingqing Zhang collected data and literature. All authors participated in writing this paper and approved the final manuscript.

Conflicts of Interest: The authors declare no conflict of interest.

\section{References}

1. Miketa, A.; Mulder, P. Energy productivity across developed and developing countries in 10 manufacturing sectors: Patterns of growth and convergence. Energy Econ. 2005, 27, 429-453. [CrossRef]

2. Solow, R.M. A Contribution to the theory of economic growth. Q. J. Econ. 1956, 70, 65-94. [CrossRef]

3. Swan, T.W. Economic growth and capital accumulation. Econ. Rec. 1956, 32, 334-361. [CrossRef]

4. Moon, Y.S.; Sonn, Y.H. Productive energy consumption and economic growth: An endogenous growth model and its empirical application. Resour. Energy Econ. 1996, 18, 189-200. [CrossRef]

5. Mielnik, O.; Goldemberg, J. Converging to a common pattern of energy use in developing and industrialized countries. Energy Policy 2000, 28, 503-508. [CrossRef]

6. Parker, S.; Liddle, B. Economy-wide and manufacturing energy productivity transition paths and club convergence for OECD and Non-OECD countries. Energy Econ. 2017, 62, 338-346. [CrossRef]

7. Apergis, N.; Christou, C. Energy productivity convergence: New evidence from club converging. Appl. Econ. Lett. 2016, 23, 142-145. [CrossRef]

8. Wan, J.; Baylis, K.; Mulder, P. Trade-Facilitated technology spillovers in energy productivity convergence Processes across EU countries. Energy Econ. 2015, 48, 253-264. [CrossRef]

9. Adhikari, D.; Chen, Y. Energy productivity convergence in Asian countries: A spatial panel data approach. Int. J. Econ. Financ. 2014, 6, 94-107. [CrossRef]

10. Mulder, P.; De, G.H.L.F.; Pfeiffer, B. Dynamics and determinants of energy intensity in the service sector: A cross-country analysis, 1980-2005. Ecol. Econ. 2014, 100, 1-15. [CrossRef]

11. Mulder, P.; De Groot, H.L.F. Sect Oral Energy and Our-Productivity Convergence. In Sustainable Resource Use and Economic Dynamics; Bretschger, L., Smulders, S., Eds.; Springer: Dordrecht, The Netherlands, 2007; pp. 165-190.

12. Yang, F.; Pan, S.; Yao, X. Regional convergence and sustainable development in China. Sustainability 2016, 8, 121. [CrossRef]

13. Markandya, A.; Pedroso-Galinato, S.; Streimikiene, D. Energy intensity in transition economies: Is there convergence towards the EU average. Energy Econ. 2006, 28, 121-145. [CrossRef]

14. Ezcurra, R. Distribution dynamics of energy intensities: A cross-country analysis. Energy Policy 2007, 35, 5254-5259. [CrossRef]

15. Le, P.Y.; Sévi, B. On the Non-Convergence of energy intensities: Evidence from a pair-wise econometric approach. Ecol. Econ. 2010, 69, 641-650.

16. Duro, J.A.; Padilla, E. Inequality across countries in energy Intensities: An analysis of the role of energy transformation and final energy consumption. Energy Econ. 2011, 33, 474-479. [CrossRef]

17. Mohammadi, H.; Ram, R. Cross-country convergence in energy and electricity consumption, 1971-2007. Energy Econ. 2012, 34, 1882-1887. [CrossRef] 
18. Herrerias, M.J. World Energy intensity convergence revisited: A weighted distribution dynamics approach. Energy Policy 2012, 49, 383-399. [CrossRef]

19. Qi, S.; Li, K. The Convergence analysis of differences of regional sectors economic growth and energy intensity. Econ. Res. J. 2010, 2, 109-122. (In Chinese)

20. Chen, X.H. Spatial Conditional B-convergence analysis of Society-wide energy efficiency based on technological diffusion. China Popul. Resour. Environ. 2013, 23, 7-13. (In Chinese)

21. Zhang, W.; Pan, X.F.; Yan, Y.B.; Pan, X.Y. Convergence analysis of regional energy efficiency in China based on large-dimensional panel data model. J. Clean. Prod. 2017, 142, 801-808. [CrossRef]

22. Mulder, P.; De, G.H.L.F. Structural change and convergence of energy intensity across OECD Countries, 1970-2005. Energ. Econ. 2012, 34, 1910-1921.

23. Maza, A.; Villaverde, J. The world per capita electricity consumption distribution: Signs of convergence. Energy Policy 2008, 36, 4255-4261.

24. Liddle, B. Electricity intensity convergence in IEA/OECD countries: Aggregate and sect oral analysis. Energy Policy 2009, 37, 1470-1478.

25. Herrerias, M.J.; Liu, G. Electricity intensity ACROSS Chinese provinces: New evidence on convergence and threshold effects. Energy Econ. 2013, 36, 268-276. [CrossRef]

26. Jiang, L.; Ji, M. China's energy intensity, determinants and spatial effects. Sustainability 2016, 8, 544. [CrossRef]

27. Teräsvirta, T. Specification, estimation and evaluation of smooth transition autoregressive models. J. Am. Stat. Assoc. 1994, 89, 208-218.

28. Van, D.D.; Franses, P.H. Modeling multiple regimes in the business cycle. Macroecon. Dyn. 1999, 3, 311-340.

29. Basile, R. Regional economic growth in Europe: A semiparametric spatial dependence approach. Pap. Reg. Sci. 2008, 87, 527-544. [CrossRef]

30. Pede, V.O.; Florax, R.J.G.M.; Lambert, D.M. Spatial econometric STAR models: Lagrange multiplier tests, monte carlo simulations and an empirical application. Reg. Sci. Urban Econ. 2014, 49, 118-128. [CrossRef]

31. China Economic Information Net Statistics Database. Available online: http:/ /www.cei.gov.cn (accessed on 31 July 2017).

32. CSY. Urban Statistical Yearbook of China; China Statistical Publishing House: Beijing, China, 2013.

33. Tang, L.; Yang, Z.L. Energy efficiency and industrial economic transition. Quant. Tech. 2009, 9, 34-48. (In Chinese) 